\title{
How Significant is the Dynamic Component of the North American Vertical Datum?
}

\author{
Research article \\ E. Rangelova ${ }^{1 *}$, W. van der Wal ${ }^{2}$ and M.G. Sideris ${ }^{1}$
}

1 Department of Geomatics Engineering, University of Calgary, 2500 University Drive NW, Calgary, AB, T2N 1N4, Canada

2 Faculty of Aerospace Engineering, Delft University of Technology, Delft, The Netherlands

\begin{abstract}
:
One of the main current geodetic activities in North America is the definition and establishment of a geoid-based vertical datum that will replace the official CGVD28 and NAVD88 datums in Canada and the USA, respectively. The new datum will also have a time-dependent (dynamic) component required by the targeted one-centimetre accuracy of the datum. Heights of the levelling benchmarks are subject to temporal changes, which contribute to the degradation of the accuracy of the datum and increase the misfit of the geoid heights determined gravimetrically and by GNSS/levelling. The zero level surface, i.e., the geoid, also changes with time, most significantly due to postglacial rebound, climate-induced loss of polar ice masses and mountain glaciers, and hydrology variations. In this study, we examine the possible changes of the datum due to the aforementioned factors. We are mostly concerned with postglacial rebound as it can contribute more than $1 \mathrm{~mm}$ per year and more than $1 \mathrm{~cm}$ per decade to the geoid change. We also assess the significance of the temporal geoid and benchmark height changes and show that, compared to its current accuracy, the geoid change is only significant after a decade mostly in the flat areas of central Canada.
\end{abstract}

\section{Keywords:}

A geoid-based vertical datum $\cdot$ GRACE $\cdot$ polar ice melt $\cdot$ postglacial rebound $\cdot$ temporal changes of the geoid

(c) Versita sp. z o.o.

Received 15-09-2012; accepted 27-12-2012

1. Introduction

A new, geoid-based vertical datum is currently being developed for Canada by the Geodetic Survey Division and will be adopted in 2013 to replace the outdated, levelling-based Canadian Geodetic Vertical Datum of 1928 (CGVD28). The USA will also replace its official vertical datum, i.e., the North American Vertical Datum of 1988 (NAVD88), with a geoid-based one in 2022 (Smith et al. 2013). The realization of the new datums by means of a geoid model will mitigate a number of theoretical inconsistencies and practical problems that the traditional levelling-based datums exhibit in North America: continental-size national vertical control networks with large systematic errors from coast to coast and regional distortions; sea surface topography ignored in the datums' defini-

*E-mail: evrangel@ucalgary.ca, Tel.: +1 4032106834 tion, which leads to distortions of the zero-height surface from an equipotential surface and geopotential values that are far from the actual values; large areas without vertical control (northern areas of Canada); rapid rate of benchmark destruction and loss; inability to provide adequate accuracy for GNSS/levelling; and large changes of heights of benchmarks due to (mostly) the postglacial rebound ongoing in the region (Véronneau and Héroux 2006).

The National Geodetic Survey (USA) and the Geodetic Survey Division (Canada) are also working on the definition and realization of the North American Vertical Reference System (NAVRS) of 2022. The new continental vertical datum will be

1. an equipotential surface defined by a local geopotential value $W_{0}$,

2. realized by a geoid model $N$ for a reference epoch $T_{0}$, and

3. supplemented by a model of the temporal geoid variations $\delta N$. 
The $W_{0}$ value will be the average potential for North America determined by averaging the local potential values at tide gauge stations along the coasts of Canada and the USA; see, e.g., Hayden et al. (this issue). The continental geoid model will be computed from the best available global geopotential models based on GOCE and GRACE and improved terrestrial gravity and topography data. The model of the temporal geoid variations will ensure that the timevariable geoid heights can be computed for an arbitrary epoch after the reference epoch $T_{0}$. This is necessary because of the prominent increase in the geoid height at a rate of approximately $1 \mathrm{~cm}$ per decade in the Hudson Bay region.

In this paper, we focus exclusively on the temporal variations of the geoid-based datum and attempt to quantify their significance in view of the current accuracy of the GNSS ellipsoidal and geoid heights. For this purpose, we study the effect on the geoid of three geophysical signals that originate from different geophysical systems: the solid Earth (postglacial rebound), the hydrosphere (longterm hydrology variations), and the cryosphere (ice mass loss in Greenland, Alaska and the Canadian ice cap). Jacob et al. (2012) examine also the importance of the groundwater withdrawal, earthquakes and volcanic activity for the geoid change in North America.

We start the paper with the theoretical relationship between the temporal changes in the ellipsoidal, orthometric and geoid heights (Section 2). Then, in Section 3, we investigate the geoid changes from the mentioned geophysical phenomena. In Section 4, we present models of absolute vertical crustal displacement by combining GRACE and GNSS data. In Section 5, we assess the significance of the temporal effects on the geoid and orthometric heights by comparison with their accuracy. Finally, conclusions are given in Section 6.

2. Relationship between temporal changes of ellipsoidal, orthometric and geoid heights

We introduce the basic concept of the temporal geoid and height changes without making assumptions regarding the nature of the dynamic process that causes these changes and its spatial scale - global, regional, or local. We assume that the following effects of the dynamic Earth are taken into account: ocean loading, solid Earth tides, pole tide, rotational deformation due to polar motion, as well as atmospheric loading (IERS Conventions 2010, Petit and Luzum 2010).

The temporal changes of the geoid, orthometric and ellipsoidal heights can be described as follows (Biró et al. 1986). At epoch $t$, an equipotential surface of the gravity field that passes through point $\mathrm{P}$ is defined by the equation $W=W_{\mathrm{P}}$. If we assume that the potential changes by a constant value $\delta W$, the equipotential surfaces are defined by $W^{\prime}=W+\delta W$ at the new epoch $t^{\prime}=t+\delta t$. With $\delta g^{T}=\left(\delta W_{x}, \delta W_{y}, \delta W_{z}\right)$ at point $\mathrm{P}$ and $\delta W_{x}=\delta W_{y}=$ $0, \delta W_{z}=\delta W=\delta g$, the change in the geoid height $\delta N$ is

$$
\delta N=\delta W / g
$$

Here we implicitly assumed that the gravity changes only due to mass redistribution and ignored a possible effect of the crustal displacement. We should note that the change in the terrestrial gravity associated with postglacial rebound is a sum of both effects, i.e., a free-air reduction component due to the change in the height of the observation station should be added to the mass change component to account for the total change in gravity as observed by an absolute gravimeter. The change in the GRACE-observed horizontal (tangential) components of the gravity vector associated with postglacial rebound in North America was investigated by van der Wal et al. (2011). They show that this change can be significant. An analysis of the effect on the geoid is left for a future study.

The change in the orthometric height of point $\mathrm{P}$ is the separation between the new equipotential surface through the new position $P^{\prime}$ of the point $P$ and the new equipotential surface at the original location, i.e.,

$$
\delta H=\left(W_{P^{\prime}}^{\prime}-W_{P}^{\prime}\right) / g=\Delta W^{\prime} / g .
$$

This equation gives the relative change in the position of point $P$ with respect to the displaced geoid. Using Eq. (4.21) from Heiskanen and Moritz (1967), it can be shown that the change in (mean) gravity has no appreciable effect on the change in the orthometric height by the following example. For $H=100 \mathrm{~m}, \Delta W^{\prime}=-0.1 \mathrm{~m}^{2} / \mathrm{s}^{2}$ and $\Delta g=g^{\prime}-g=-10^{-8} \mathrm{~m} / \mathrm{s}^{2}$, the change in the orthometric height is $\delta H=0.01 \mathrm{~m}$ with the change in gravity contributing only $10^{-7} \mathrm{~m}$.

Finally, the absolute vertical displacement, $\delta h$, can be determined from a simple relationship as follows:

$$
\delta h=\delta N+\delta H
$$

In the pre-GNSS era, Eq. (3) was used for the determination of the absolute vertical displacement from measured change in the orthometric height and computed change in the geoid height usually by integrating measured gravity changes. One should note that $\delta H$ should include the height change of the origin of the vertical control network. Nowadays, the absolute crustal displacement is determined by GNSS, and the change in the geoid height can be obtained from GRACE satellite gravity data. Therefore, $\delta H$ can be easily obtained without the need of precise re-levelling by

$$
\delta H=\delta h-\delta N
$$

So far we have assumed that the geoid and heights are given in the same tidal system. Ekman (1989), Poutanen et al. (1996) and Sun and Sjöberg (2001), among others, give the following three concepts of tidal systems. A mean tidal geoid contains the permanent tide (the time-independent part of the tide-generating potential of the Sun and the Moon) and the permanent tidal deformation; a non-tidal geoid is free from both the permanent tide

\section{VERSITA}


and deformation; a zero tidal geoid contains only the permanent tidal deformation; see Fig. 3 by Poutanen et al. (1996). A zero tidal crust differs from a non-tidal crust by the permanent tidal deformation. A mean tidal crust is identical to a zero crust.

The consistency of the tidal systems of the measurement data sets is crucial for the accuracy of the determined temporal geoid and height changes. According to Ekman (1989), tidal inconsistencies larger than the standard error of the vertical crustal displacement can introduce distortions of a north-south orientation in the estimated displacements. Moreover, such inconsistencies are likely to introduce systematic distortions in the vertical datum. The potential $W_{0}$ that defines a levelling-based vertical datum is affected by the change in the potential of the local mean sea level and the crustal displacement of the datum origin. On the other hand, if the datum is geoid-based, the permanent tide can introduce a decimetre error in the orthometric height differences obtained by means of GNSS positioning and a geoid model in the Nordic countries as shown by Ekman (1989). In addition, the systematic errors in the orthometric heights (and gravity) from the inconsistencies in the tidal corrections may propagate in the geoid model through the gravity reductions. Therefore, it is very important that the ellipsoidal, orthometric and geoid heights refer to the same tidal system in a geoid-based datum if a centimetre absolute accuracy in the GNSSdetermined orthometric height is needed.

The GNSS ellipsoidal heights refer to a non-tidal crust (IERS Conventions 2010, Petit and Luzum 2010). Orthometric heights in North America have the astronomic (tidal) correction applied and hence they also refer to a non-tidal crust. It is assumed that a regional gravimetric geoid model inherits the tidal system of the global geopotential model used to define the long and medium wavelengths of the geoid. The geopotential models are distributed in a non-tidal or zero tidal system. The transformation between the two systems is performed by correcting the spherical harmonic coefficient of degree two and order zero (IERS Conventions 2010, Petit and Luzum 2010).

\section{Evaluation of the geoid changes}

In this section we study and discuss the effect on the geoid of the three geophysical signals described in Section 1. The three of them act on a different time scales: secular, long-term and decadal or inter-decadal.

\subsection{Geoid change due to postglacial rebound}

For the last decade, the Gravity Recovery and Climate Experiment (GRACE, Tapley et al. 2004b) satellite mission has been facilitating the estimation of the global and regional geoid changes by a stream of monthly-averaged spherical harmonic coefficients of the geopotential. The geoid rate of change $\dot{N}(\varphi, \lambda)$ at a point with geodetic latitude $\varphi$ and longitude $\lambda$ can be computed as follows (e.g., Rangelova and Sideris 2008):

$\dot{N}(\varphi, \lambda)=R \sum_{l=2}^{L} \sum_{m=0}^{l} \tilde{P}_{l m}(\sin \varphi)\left[\dot{C}_{l m} \cos (m \lambda)+\dot{S}_{l m} \sin (m \lambda)\right]$,

where $\dot{C}_{l m}$ and $\dot{S}_{l m}$ are the time derivatives (rates) of the fully normalized GRACE spherical harmonic coefficients of the geopotential, $\tilde{P}_{l m}(\sin \varphi)$ is the fully normalized associated Legendre function of degree $l$ and order $m ; R$ is a mean radius of the Earth, and $L$ is the maximum spherical harmonic degree of the GRACE model.

Maps of GRACE-determined geoid rates similar to the one shown in Fig. 1 are not easily interpretable due to a variety of factors. The GRACE satellite measurements are of integral nature, meaning that at a certain location along the orbit GRACE measures superimposed gravity signals and averages them. Thus, the separation of different signals originating from the solid Earth, the oceans, the hydrosphere, and the atmosphere is practically impossible without the use of models of these signals. Moreover, the post-processing of the distributed spherical harmonic coefficients of the geopotential by the GRACE processing centers, which routinely involves smoothing of random and correlated errors (e.g., Swenson and Wahr 2006), ultimately leads to leakage of adjacent signals over the territory of interest. Moreover, the patterns and magnitude of the geoid rates depend heavily on the post-processing strategies and filtering of the spherical harmonic coefficients.

Figure 1 shows the average geoid rates for North America from six monthly solutions (CSR, GFZ, JPL, DMT-1, AIUB, and ITG) obtained from the International Centre for Global Earth Models (ICGEM, http: //icgem.gfz-potsdam.de/ICGEM/) for a common time period of January 2003 to December 2009. The solutions are filtered by Kusche's $k$-filter (Kusche et al. 2009) and have an approximate spatial resolution of $340 \mathrm{~km}$. Three distinct, high-magnitude mass change signals are observed for North America: the mass increase that is related to the postglacial rebound flow of mantle mass towards the center of the Hudson Bay region (e.g., Steffen et al. 2009), the ice mass retreat from Alaska's glaciers (e.g., Tamisiea et al. 2005), and Greenland's ice mass loss signal (e.g., Luthcke et al. 2006). Long-term hydrology variations may also exist, but it is difficult to separate them from the secular geodynamic and climaterelated signals unless a reliable hydrology model is available. More discussion on this is given in Section 3.2.

Figure 2 shows a map of the standard deviation of the geoid rates computed from the six solutions as a measure of the models agreement. The characteristic pattern of the an-isotropic and latitudedependent $k$-filter is easily observed. More importantly, it can also be observed that the disagreement of the models can reach 15$30 \%$ of the geoid rate magnitude in the vicinity of Hudson Bay. The errors shown in the figure are responsible for large deviations of the pattern of postglacial rebound and the locations of the North American ice sheet domes, as well as the differences in the magnitude of the signal. Observe, for example, the $0.3 \mathrm{~mm} / \mathrm{yr}$ error north- 


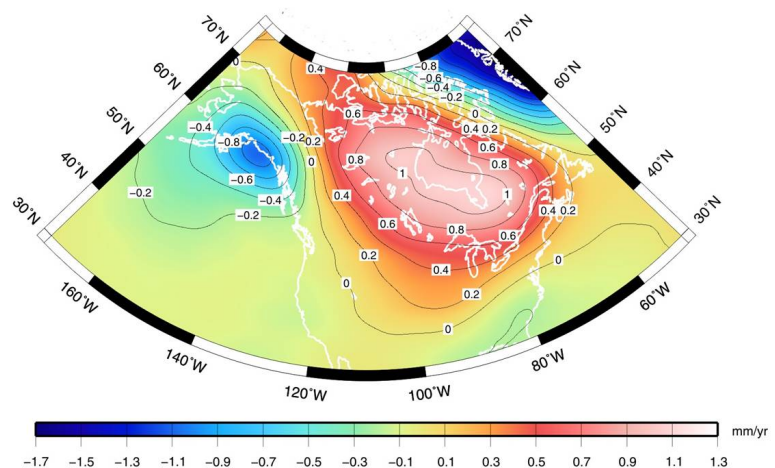

Figure 1. 2003-2009 GRACE-derived geoid rates for North America computed by averaging six monthly GRACE solutions; unit is $\mathrm{mm} / \mathrm{yr}$.

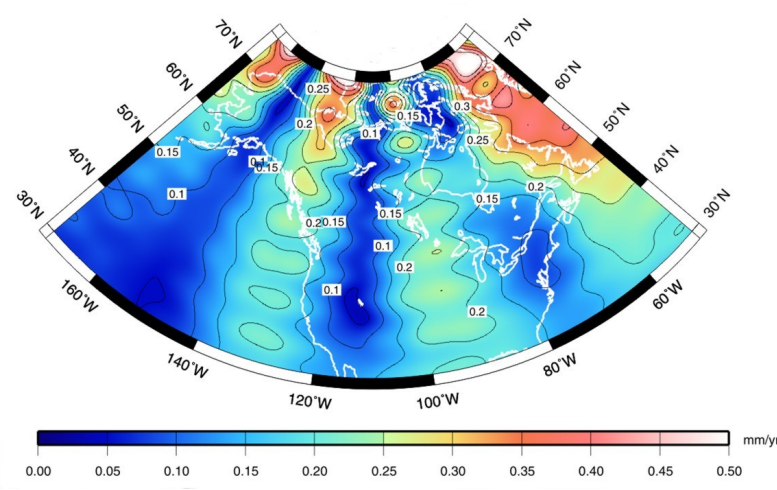

Figure 2. Standard deviations of the GRACE-derived geoid rates computed from the differences of the six solutions and the average rates in Fig. 1 ; unit is $\mathrm{mm} / \mathrm{yr}$.

west of Hudson Bay, which is the approximate location of a peak signal associated with an ice dome in the ICE5G model of Peltier (2004), on the existence of which the different GRACE solutions disagree.

\subsection{Geoid change due to hydrology long-term variations}

We assess the hydrology long-term variations in North America by means of the GLDAS model developed by Rodell et al. (2004). GLDAS is a land surface, global hydrology model based on assimilation of satellite and ground data. We use model outputs that consist of four layers of soil moisture, snow water equivalent, and canopy water storage. GLDAS does not include ground water and water transport. This model has been extensively used for evaluation of the global GRACE-observed water mass variability; see, e.g., Tapley et al. (2004a) and Syed et al. (2008).

We use the monthly GLDAS total water storage fields for 8 years from 2003 to 2010. For the purpose of our analysis, we convert the

VERSITA

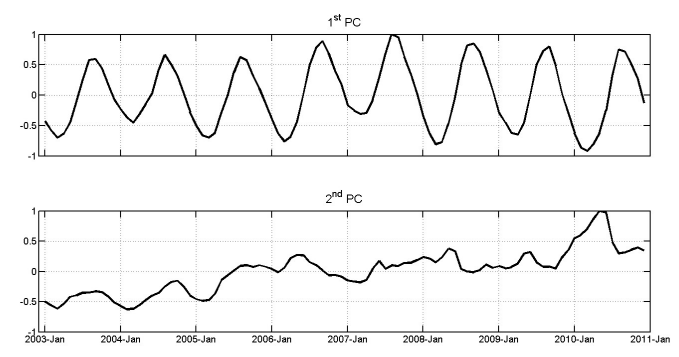

Figure 3. Time evolution of the first two GLDAS modes of variability. The second plot shows a long-term hydrology variation, where the computed trend of the principal component is $0.1 \mathrm{yr}^{-1}$.

GLDAS fields to spherical harmonic coefficients of the geopotential, from which the geoid variations are computed by means of Eq. (5). Using principal component analysis, we extract the longterm (and trend-like) geoid variations that show up in the second mode of the GLDAS data eigen-spectrum; see the second plot in Fig. 3. Note that this long-term mode of variability is much less significant (in terms of data variance) than the annual cycle shown in the same figure: about $66 \%$ of the total water variability is due to the annual variations while only $15 \%$ are explained by the longterm variations.

The pattern of the long-term signal is shown in Fig. 4. A large geoid growth is observed north of Hudson Bay most likely due to GLDAS model flaws in the northern areas covered by ice. It is believed that the mass decrease in Alaska is also not realistic (Lutchke et al. 2008, p.773). In general, trends in high latitudes are not reliable as hydrology models do not describe permanent snow well. On the other hand, the small positive geoid change of $0.1 \mathrm{~mm} / \mathrm{yr}$ located between Lake Winnipeg and Hudson Bay is likely a real signal. A negative geoid change of $-0.2 \mathrm{~mm} / \mathrm{yr}$ is observed in the Great Lakes area and in eastern Canada. In the USA, a positive geoid signal $(0.1 \mathrm{~mm} / \mathrm{yr})$ is found in the Cordillera while the eastern US territories show a geoid decrease of $-0.2 \mathrm{~mm} / \mathrm{yr}$ (also observed in the southeastern US in Fig. 1).

\subsection{Geoid change due to ice mass loss signal}

The ice melt in Greenland, Alaska, and the Canadian ice cap induces a change in the gravitational potential and a displacement of the Earth crust due to redistribution of masses from ice sheets to ocean areas. The change in sea level that is consistent with the new equipotential is computed here by solving the so-called 'sea level equation' (Farrell and Clark 1976). In the computation, elastic load Love numbers for a compressible Earth based on the Preliminary Reference Earth Model are used (computed by P. Gegout, http: //gemini.gsf c.nasa.gov/aplo/).

The change in the surface load also induces a change in the rotational state of the Earth (Wu and Peltier 1984). This feedback 


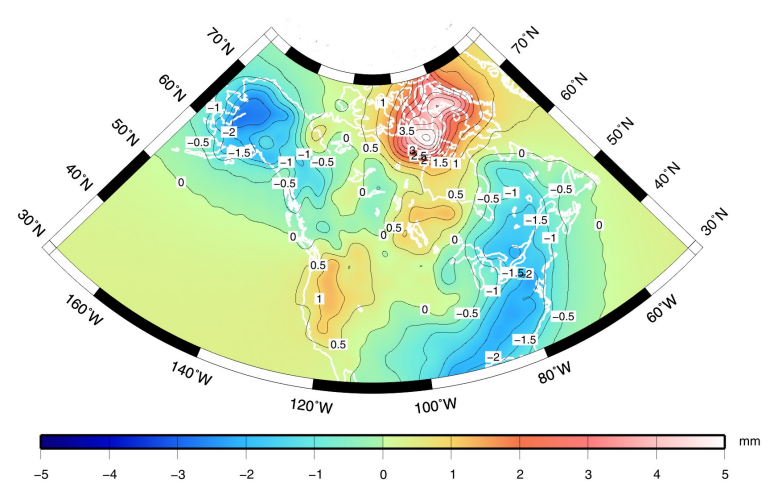

Figure 4. Pattern of the long-term hydrology variation. To compute the trend, one should multiply the pattern by the trend of $0.1 \mathrm{yr}^{-1}$ of the second principal component in Fig. 3.

mechanism has a small effect on the shape of the sea level, but it is nevertheless included, except for the change in the centrifugal potential which does not influence the GRACE measurements (Tamisiea 2011). Tidal Love numbers are computed for an Earth model used in a recent benchmark paper (Spada et al. 2011). Motion of the solid Earth with respect to the Earth center of mass is also included. Although this effect is not sensed by GRACE directly, it affects higher degree terms through the feedback with the sea level.

Figure 5 shows the change in the geoid due to the ice melt in Greenland and Alaska. Greenland's signal is simulated by means of a GRACE-based ice mass loss model developed by Jensen (2010) with a melt rate of $217 \pm 23 \mathrm{Gt} / \mathrm{yr}$. Alaska's signal is simulated by means of the estimate of $84 \mathrm{Gt} / \mathrm{yr}$ ice mass loss by Lutchke et al. (2008) and assuming uniform ice melting. In the figure, similar geoid rates are observed for the Atlantic and Pacific Canadian coasts: $-0.5 \mathrm{~mm}$ for the northern shores to $0.1 \mathrm{~mm} / \mathrm{yr}$ for the southern shores. In the Arctic, the geoid rate is mostly -0.5 to $-0.2 \mathrm{~mm} / \mathrm{yr}$ but reaches $-1 \mathrm{~mm} / \mathrm{yr}$ over Baffin Island. We also simulated the melt of the Canadian ice cap glaciers (not shown in Fig. 5) using the ice mass loss estimates of $37 \mathrm{Gt} / \mathrm{yr}$ for the northern Canadian Arctic Archipelago given by Gardner et al. (2012). The maximum geoid decrease over the northern Archipelago is $-1.2 \mathrm{~mm} / \mathrm{yr}$. These ice mass loss rates are non-linear with time and depend on the future climate (Jacob et al. 2012).

\section{A model of absolute vertical crustal displacement}

A model of absolute vertical displacement can be computed from a combination of GRACE-derived rates and GNSS-determined vertical crustal velocities. The former allows one to obtain a discontinuous signal while the use of the latter can mitigate the GRACE leakage effects and ensure a more precise localization of the postglacial rebound domes as well as the line of zero motion that separates the areas with crustal uplift from the peripheral subsiding

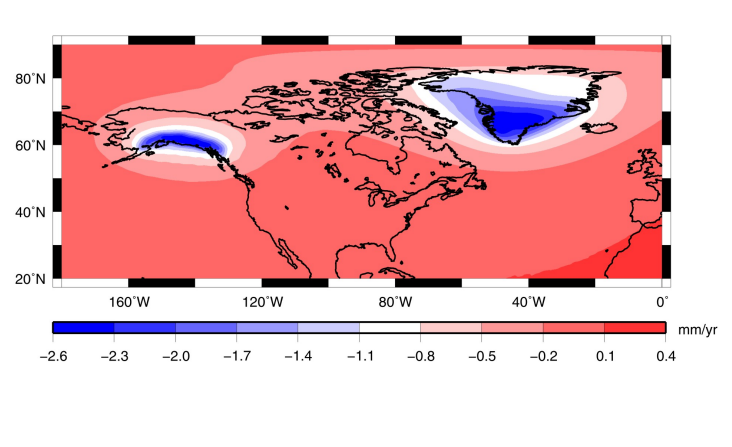

Figure 5. Rate of the geoid change due to ice mass loss in Greenland and Alaska; unit is $\mathrm{mm} / \mathrm{yr}$.

areas. The GRACE rates and GNSS velocities can be combined optimally by means of least-squares adjustment where the velocity surface is parameterized using local radial-base functions placed uniformly in the area of interest. The computational procedure is described in detail by Rangelova et al. (2009).

Before performing the combination procedure, an assessment of the agreement of the GRACE rates and GNSS velocities is necessary. This is important in view of the fact that the GRACE rates are biased with respect to the vertical velocities due to leakage effects that are difficult to quantify and due to the omission of the degree one term. GRACE does not observe the geocentre motion and, thus, changes in the degree one spherical harmonics cannot be computed from GRACE. On the other hand, postglacial rebound, among other geophysical processes, induces a geocentre motion; a collection of values of predicted secular geocenter motion is given by Wu et al. (2012, Table 3). Differences between the GRACE rates and GNSS velocities will also include the drift of the origin of the GNSS reference frame with respect to the center of masses. For example, it was found that the origin of ITRF2008 is in agreement with the center of masses at the level of $0.5 \mathrm{~mm} / \mathrm{yr}$ (Wu et al. 2011). The bias of the GRACE rates will displace the line of zero motion and will decrease/increase the magnitude of the peak signal in the Hudson Bay region.

Another important fact to consider is the effect of the hydrology correction on the GRACE rates. Our results from the comparison with the GNSS velocities show that the GLDAS hydrology correction results in an overall increase of the standard deviation of the differences between the rates and velocities. Similar results were found by van der Wal et al. (2011, Fig. 6). This correction generally improves the agreement for the southern regions, where smaller velocities are measured and worsens the agreement for the northern regions with larger vertical velocities. Thus, the GRACE data should not be corrected for the hydrology signal (our preferred option) or this correction should be performed with caution. 

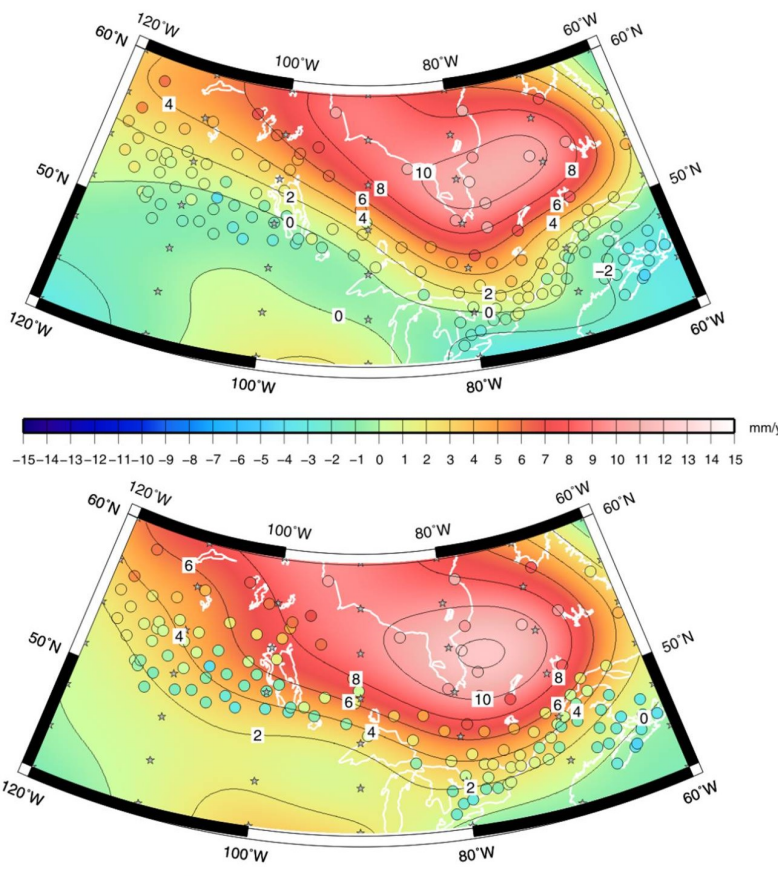

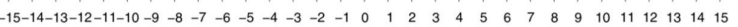

Figure 6. Upper plot: Combined GRACE and GNSS vertical displacement rates; unit is $\mathrm{mm} / \mathrm{yr}$; Lower plot: GRACE CSR $\mathrm{RL} 04$ vertical displacement rates overlaid with $\mathrm{CBN}$ vertical velocities; unit is $\mathrm{mm} / \mathrm{yr}$.

Finally, some details for both data sets are given. The GRACE vertical displacement rates are computed from the $k$-filtered CSR RL04 solution by the conversion given by Wahr et al. (1995). The spatial resolution of the rates is approximately $340 \mathrm{~km}$. Vertical velocities for 150 Canadian Base Network (CBN) GNSS stations are obtained from GEODVEL1b (Argus et al. 2010; Argus and Peltier 2010). The estimated bias of the GRACE rates with respect to the vertical velocities is $3 \mathrm{~mm} / \mathrm{yr}$ and slightly increases to $3.6 \mathrm{~mm} / \mathrm{yr}$ when the GLDAS correction is applied. All differences larger than $6 \mathrm{~mm} / \mathrm{yr}$ are considered outliers and excluded from the optimal combination procedure.

The combined vertical displacement rates are given in the upper plot of Fig. 6, and the GRACE rates are shown in the lower plot of Fig. 6. Both patterns agree well in Hudson Bay but disagree in the areas south of Hudson Bay including the Great Lakes region. The shape and the gradient of the GRACE pattern are slightly corrected in the combined solution and the line of zero motion is placed in the Great Lakes and through the prairies on the west.

\section{Significance of the vertical displacement and geoid change}

We assess the significance of the postglacial rebound signal by comparison with the calibrated errors of the three height components at 224 GNSS benchmarks in eastern and central Canada.

\section{VERSITA}

The GNSS ellipsoidal heights are obtained from the network SuperNet (Craymer and Lapelle 1997) v.5.3.1 and are determined in the reference frame ITRF2005(2006.0). Corrections for the vertical crustal motion are applied in the course of the adjustment of the network using a crustal velocity model based on a decade of GPS repeat and continuous measurements across Canada. The orthometric heights are from the Nov07 adjustment of the first order vertical control network in Canada that includes only levelling measurements after 1981. The effect of postglacial rebound on the orthometric heights is thus significantly reduced, but the levelling measurements are not corrected for the crustal motion. The geoid heights are interpolated from the official gravimetric geoid model for Canada, CGG2010 (Huang and Véronneau 2013). It can be expected that the geoid height is the least affected by the postglacial rebound height component. Firstly, the geoid secular rate is one order of magnitude smaller than the vertical crustal motion (compare Figs. 1 and 6), and, secondly, the regional geoid model was computed with the latest GRACE global geopotential model available at the time of the CGG2010 development. Largely unknown remains the effect of postglacial rebound on the terrestrial gravity anomalies (through inconsistencies of the measurement epochs of the terrestrial gravity) that is propagated in the regional geoid solution. An attempt to quantify this effect was made by Ali (2006).

We compute the geoid height differences at each GNSS benchmark using the relationship in Eq. (3), here modified as $(h-H)$ - $N$, where $h$ is the GNSS ellipsoidal height, $H$ is the orthometric height and $N$ is the geoid height. Two outliers are removed after a 3 -sigma test on the geoid height differences. The estimated mean in the weighted least-squares adjustment is the offset of the Nov07 vertical datum with respect to the equipotential surface defined by CGG2010. The calibrated standard deviations of the ellipsoidal, orthometric and geoid heights are computed by means of variance component estimation using the available diagonal variancecovariance matrices. The procedure is described in (Rangelova et al. 2010). One should note that the use of only the variances in the variance component estimation procedure results in optimistic calibrated standard deviations as opposed to the use of fullypopulated variance-covariance matrices which provides more realistic errors. However, fully-populated variance-covariance matrices are rarely available.

The estimated scale factors of the variance-covariance matrices are as follows: SuperNet v.5.3.1: 0.85 \pm 0.62 ; Nov07: $0.61 \pm 0.16$ and CGG2010: 0.39 \pm 0.46 . With these scale factors, smaller calibrated standard deviations are computed than the initial values. The maximum error of $50 \mathrm{~mm}$ belongs to the orthometric heights of the benchmarks located north and northwest of Lake Superior as the levelling errors propagate west of the origin of the vertical control network at Rimouski, Quebec, Canada. The maximum standard deviation for the ellipsoidal heights is $30 \mathrm{~mm}$, and the maximum error for the geoid heights is $20 \mathrm{~mm}$. The geographical distribution of the errors of the geoid and orthometric heights can be seen in Fig. 7. This figure includes also plots of the ratio of the decadal 

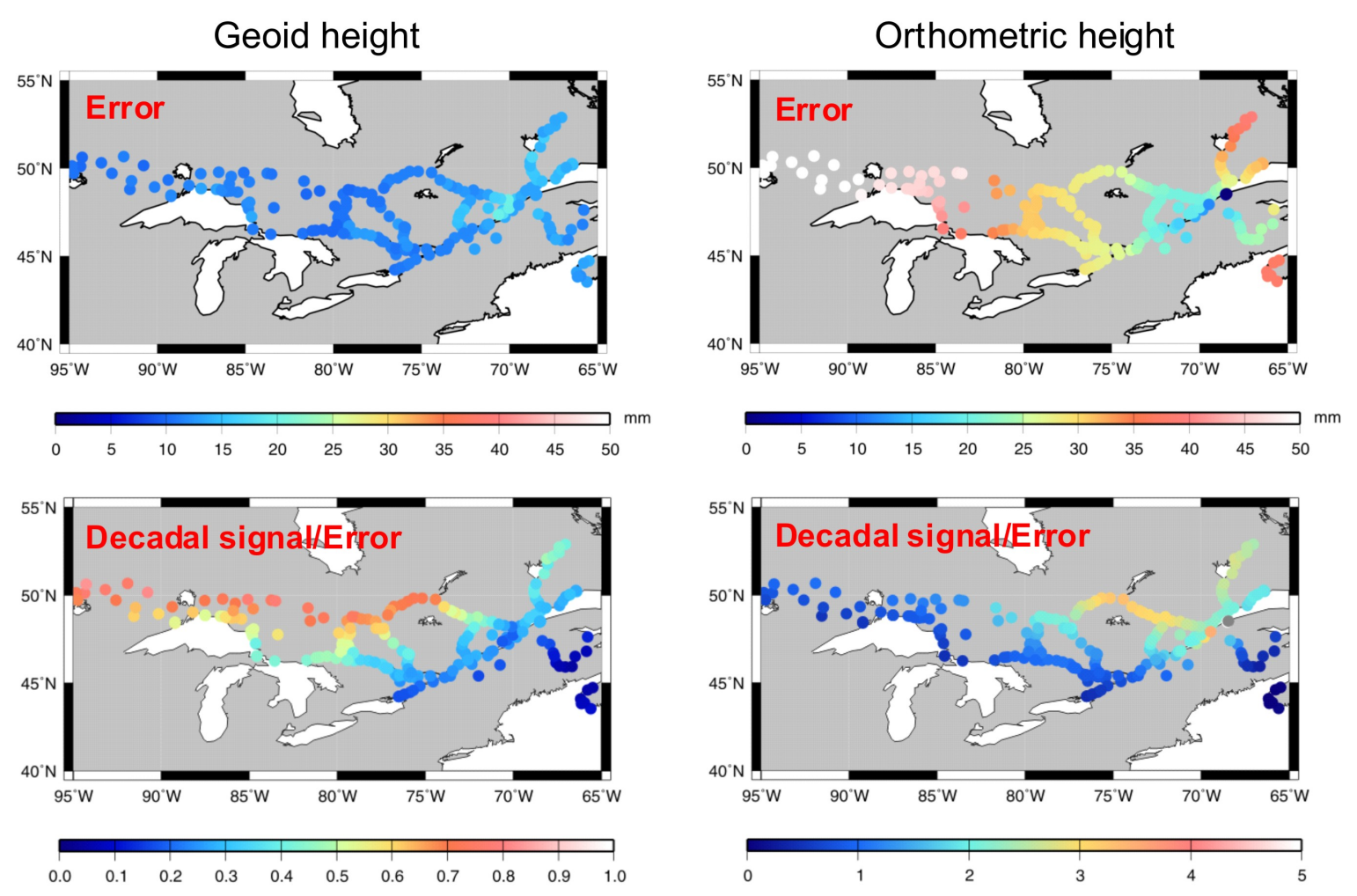

Figure 7. Upper plots: calibrated standard deviations of the geoid and orthometric heights; unit is $\mathrm{mm}$. Lower plots: ratios of the decadal postglacial rebound signal and the standard deviations for the geoid and orthometric heights.

postglacial rebound signal (obtained from the models in Fig. 1 and Fig. 6-upper plot) and the calibrated standard deviations of the geoid and orthometric heights computed at each benchmark. Evidently, a ratio larger than one infers that the secular geodynamic signal is significant. It can easily be observed that the geoid change is only significant in the flat areas of central Canada, where the geoid error approaches $1-2 \mathrm{~cm}$. More significant is the change in the orthometric heights (and ellipsoidal heights), for which the vertical crustal displacement in eastern Canada after 10 years becomes 3 times larger than the errors of the orthometric heights.

The implication of these results is that if the geoid-based vertical datum is updated every 10 years by means of a regional (or continental) geoid model computed with up to date global geopotential models (possibly from a GRACE follow-on satellite mission) and corrected for the postglacial rebound signal terrestrial data, the datum will be free of the secular geodynamic effect. Otherwise, the geoid model must be supplemented and distributed together with a model of its secular changes.

\section{Conclusions}

The new geoid-based vertical datum for Canada, which will be adopted in 2013, requires that the temporal effects on the datum be quantified and their significance be carefully assessed. This is also important in view of the current work towards the definition and realization of a geoid-based datum for the North American continent. In this study, we focused on three temporal effects on the geoid, orthometric and ellipsoidal heights: the secular postglacial rebound signal, the melting of the polar ice masses and those in the mountain glaciers in Alaska, and the long-term hydrology variations. In terms of their importance only the postglacial rebound signal is large enough that should be considered in a dynamic geoid-based vertical datum. The geoid needs to be corrected every 10 years while this is necessary much more often for the GNSS ellipsoidal heights and the orthometric heights.

The second examined process, i.e., the long-term hydrology variations are not large enough to be included in the model of the temporal geoid changes. The decadal effect approaches 1-2 mm. This, as well as the fact that a hydrology system can experience periods of droughts followed by a restoration of the normal state of the water content, suggests that trends similar to those observed in Fig. 4 are unlikely to exist on larger than a decade time periods.

Finally, the decadal change in the geoid due to the melting of the ice masses varies from -5 to $1 \mathrm{~mm}$ along the Atlantic and Pacific coasts of Canada, but these may change depending on the future climate as the rates are non-linear. These values correspond to $0.05 \mathrm{~m}^{2} / \mathrm{s}^{2}$ and $0.01 \mathrm{~m}^{2} / \mathrm{s}^{2}$ change per decade in the $W_{0}$ value that 
defines the datum equipotential surface. One should note that the accuracy of the computed $W_{0}$ potential from, e.g., tide gauge mean sea level averages and GNSS ellipsoidal heights, is poorer than $0.1 \mathrm{~m}^{2} / \mathrm{s}^{2}$. Although irrelevant for practical users, models of these dynamic effects are available and can be distributed with the geoid model for precise scientific investigations.

\section{Acknowledgements}

This work is financially supported by the European Space Agency's STSE-GOCE Height System Unification project. We thank the Geodetic Survey Division, Natural Resources Canada, for providing the data sets of the ellipsoidal and orthometric heights as well as the CGG2010 geoid model. We also thank the following people: D. Argus (JPL) for the GEODVEL1b solution, Eva Börgens (Universität Bonn) for the $k$-filtered GRACE solutions from the different processing centres, and Laura Jensen (Universität Bonn) for the Greenland ice loss model. The two reviewers are acknowledged for providing insightful comments.

The GLDAS data are obtained from ftp://agdisc.gsfc. nasa.gov/data/s4pa/GLDAS_SUBP/GLDAS_NOAH10_M/.

\section{References}

Ali l., 2006, A globally consistent and dynamic Canadian gravity reference frame for a modern heighting system and other applications, MSc thesis, University of York, Toronto.

Argus D.F., Gordon R.G., Heflin M.B., Eanes R.J., Ma C., Willis P., Peltier W.R. and Owen S.E., 2010, The angular velocity of the plates and the velocity of Earth's center from space geodesy, Geophys. J. Int., 180, 913-960, doi:10.1111/j.1365-246X.2010-x.

Argus D.F. and Peltier W.R., 2010, Constraining models of postglacial rebound using space geodesy: a detailed assessment of model ICE-5G (VM2) and its relatives, Geophys. J. Int., 181, 697-723, doi: 10.1111/j.1365-246X.2010.04562.x.

Biró P., Heck B. and Thông N.C., 1986, On a new approach into the solution of the three-dimensional geodetic-geodynamic boundary value problem, AVN- Int. Edition, 3, 9-21.

Craymer M.R. and Lapelle E., 1997, The GPS Supernet: An Integration of GPS Projects Across Canada, Internal Report, Geodetic Survey Division, Geomatics Canada, Ottawa.

Ekman M., 1989, Impacts of geodynamics phenomena on systems for heights and gravity, Bull. Geod., 63, 281-293.

Farrell W.E. and Clark J.A., 1976, On postglacial sea-level, Geophys. J., 46.
Gardner A.S., Moholdt G., Wouters B., Wolken G.J., Burgess D.O., Sharp M.J, Cogley J.G., Braun C. and Labine C., 2012, Sharply increased mass loss from glaciers and ice caps in the Canadian Arctic Archipelago, Nature Geosci., 473, 357-160.

Hayden T., Rangelova E., Sideris M.G. and Véronneau M., 2012, Evaluation of $W_{0}$ using Canadian tide gauges and GOCE gravity field models, J Geod. Sci. 2, 4, 290-301.

Heiskanen W.A. and Mortiz H., 1967, Physical Geodesy, WH Freeman, San Francisco, USA, Reprint, Technical University, Graz, Austria, 1999.

Huang J. and Véronneau M., 2013, Canadian Gravimetric Geoid Model 2010, J. Geod. (in press).

Jacob T., Wahr J., Gross R. and Swenson S., 2012, Estimating geoid height change in North America: past, present and future, J. Geod. 86, 337-358, DOI 10.1007/s00190-011-0522-7.

Jensen L., 2010, Schätzung der Eismassenbilanz von Grönland mit Hilfe von GRACE und komplementären Daten, Masterarbeit, Universität Bonn.

Kusche J., Schmidt R., Petrovic S. and Rietbroek R., 2009, Decorrelated GRACE Time-Variable Gravity Solutions by GFZ, and their Validation using a Hydrological Model, J. Geod. 83, 903-913, doi:10.1007/s00190-009-0308-3.

Luthcke S.B., Arendt A.A., Rowlands D.D., McCarthy J.J. and Larsen C.F., 2008, Recent glacier mass changes in the Gulf of Alaska region from GRACE mascon solutions, J. Glaciology, 54, 767-777.

Luthcke S.B., Zwally H.J., Abdalati W., Rowlands D.D., Ray R.D., Nerem R.S., Lemoine F.G., McCarthy J.J. and Chinn D.S., 2006, Recent Greenland Ice Mass Loss by Drainage System from Satellite Gravity Observations, Science, 314, 1,286-1,289.

Peltier W.R., 2004, Global glacial isostasy and the surface of the ice-age earth: the ICE-5G (VM2) model and GRACE, Ann. Rev. Earth planet. Sci., 32, 111-149.

Petit G. and Luzum B. (eds.), 2010, IERS Conventions 2010, IERS Technical Note 36. Verlag des Bundesamtes für Kartographie und Geodäsie, Frankfurt am Main.

Poutanen M., Vermeer M. and Mäkinen J., 1996, The permanent tide in GPS positioning, J. Geod., 70, 8, 499-504.

Rangelova E., Fotopoulos G. and Sideris M.G., 2009, On the use of iterative re-weighting least-squares and outlier

\section{VERSITA}




\section{Journal of Geodetic Science}

detection for empirically modelling rates of vertical displacement, J. Geod. 83, 523-535.

Rangelova E., Fotopoulos G. and Sideris M.G., 2010, Implementing a dynamic geoid as a vertical datum for orthometric heights in Canada, In: IAG Symposia, Vol. 135, Mertikas, S.P.P. (Ed.), Gravity, Geoid and Earth Observation, IAG Commission 2 Gravity Field, Chania, Greece, June 23-27, 2008, Springer, 295-302.

Rangelova E. and Sideris M.G., 2008, Contributions of surface measurements and GRACE data to the study of the secular geoid changes in North America, J. Geodyn., 46 (3-5), 131-143, doi: 10.1016/j.jog.2008.03.006

Rodell M., Houser P.R., Jambor U., Gottschalck J., Mitchell K., Meng C.-J., Arsenault K., Cosgrove B., Radakovich J., Bosilovich M., Entin J.K., Walker J.P., Lohmann D. and Toll D., 2004, The Global Land Data Assimilation System, Bull. Amer. Meteor. Soc., 85, 3, 381-394.

Smith, D.A., Véronneau, M., Roman, D.R., Huang, J., Wang, Y.M. and Sideris M.G., 2013, Towards the unification of the vertical datum over the North American continent, In: Altamimi and Collilieux (eds.), Reference Frames for Applications in Geosciences, IAG Symposia 138, DOI 10.1007/978-3-64232998-2_36.

Spada G., Barletta V.R., Klemann V., Riva R.E.M., Martinec Z., Gasperini P., Lund B., Wolf D., Vermeersen L.L.A. and King M.A., 2011, A benchmark study for glacial isostatic adjustment codes, Geophys. J. Int., 185, 106-132.

Steffen H., Petrovic S., Muller J., Schmidt R., Wunsch J., Barthelmes F. and Kusche J., 2009, Significance of secular trends of mass variations determined from GRACE solutions, J. Geodyn., 48, 157-165.

Sun W. and Sjöberg L., 2001, Permanent components of the crust, geoid and ocean depth tides, J. Geodyn., 31, 323-339.

Swenson S. and Wahr J., 2006, Post-processing removal of correlated errors in GRACE data, Geophys. Res. Lett., 33, L08402, doi:10.1029/2005GL025285.

Syed T.H., Famiglietti J.S., Rodell M., Chen J. and Wilson C.R., 2008, Analysis of terrestrial water storage changes from GRACE and GLDAS, Water Resour. Res., 44, W02433, doi:10.1029/2006WR005779.
Tamisiea M.E., 2011, Ongoing glacial isostatic contributions to observations of sea level change, Geophys. J. Int., 186, $1,036-1,044$.

Tamisiea M.E., Leuliette E.W., Davis J.L. and Mitrovica J.X., 2005, Constraining hydrology and cryospheric mass flux in southeastern Alaska using space-based gravity measurements, Geophys. Res. Lett., 32, L20501, doi:10.1029/2005GL023961.

Tapley B.D., Bettadpur S., Ries J.C., Thompson P.F. and Watkins M.M., 2004a, GRACE Measurements of Mass Variability in the Earth System, Science, 305, 503-505, doi: 10.1126/science.1099192.

Tapley B.D., Bettadpur S., Watkins M. and Reigber C., 2004b, The gravity recovery and climate experiment: Mission overview and early results, Geophys. Res. Lett., 31, L09607, doi:10.1029/2004GL019920.

van der Wal W., Kurtenbach E., Kusche J. and Vermeersen B., 2011, Radial and tangential gravity rates from GRACE in areas of glacial isostatic adjustment, Geophys. J. Int., doi: 10.1111/j.1365-246X.2011.05206.x.

Véronneau M. and Héroux P., 2006, Canadian Height Reference System Modernization: Rational Status and Plans, Report Natural Resources of Canada, Ottawa, Ontario, Canada, http://www.geod.nrcan.gc.ca/hm/pdf/ geocongres_e.pdf.

Wahr J., DaZhong H. and Trupin A., 1995, Prediction of vertical uplift caused by changing polar ice volume on a viscoelastic Earth, Geophys. Res. Lett., 22, 977-980.

Wu X., Collilieux X., Altamimi Z., Vermeersen B.L.A., Gross R.S. and Fukumori I., 2011, Accuracy of the International Terrestrial Reference Frame origin and Earth expansion, Geophys. Res. Lett., 38, L13304, doi:10.1029/2011GL047450.

Wu P. and Peltier W.R., 1984, Pleistocene deglaciation and the earth's rotation: a new analysis, Geophys. J. R. Astr. Soc., 76, 753-792.

Wu X., Ray J. and van Dam T., 2012, Geocenter motion and its geodetic and geophysical implications, J. Geodyn., 58, 44-61. 